\title{
TIC para manutenção dos estudos em período de pandemia na Universidade Federal da Bahia
}

\section{Monaliza Gomes da Conceição}

Mestranda em Educação, pela

Universidade Federal da Bahia (UFBA).

Graduada Tecnóloga em Administração

de Pequenas e Médias Empresas, pela

Universidade Norte do Paraná

(UNOPAR). Membro do Laboratório de

Tecnologias Informacionais e Inclusão

Sociodigital (LTI Digital) da Universidade Federal da Bahia (UFBA).

monaliza conceicao@hotmail.com

\section{Ucineide Rodrigues Rocha Moreira}

Mestra em Educação, pela Universidade Federal de Sergipe (UFS). Graduada em Pedagogia, pela Universidade Federal do Amazonas (UFAM). Membro do Laboratório de Tecnologias Informacionais e Inclusão Sociodigital (LTI Digital) da Universidade Federal da Bahia (UFBA).

ucirocha40@gmail.com

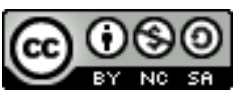

Este trabalho está licenciado com uma Licença Creative Commons - AtribuiçãoNãoComercial-Compartilhalgual 4.0

Internacional.

\section{Resumo}

Uma das formas que o ensino no Brasil encontrou para se manter no período de isolamento causado pela pandemia do Coronavírus, foi por meio de aulas remotas aderidas por algumas Instituições de Ensino Superior, em sua maioria, privadas. A Universidade Federal da Bahia, porém, manteve, por iniciativa de alguns professores, alguns momentos de aula neste formato remoto mediados por TIC, utilizando-se do sistema Moodle, um Ambiente Virtual de Aprendizagem - AVA, do qual já era usuária. Este artigo apresenta a discussão dos impactos que o COVID -19 gerou na Educação no Brasil, as políticas públicas criadas para orientar a realidade de isolamento social e como os sistemas de informação pertencentes na UFBA foram utilizados neste período de pandemia. Trata-se de uma pesquisa bibliográfica em torno de diferentes legislações, com uma abordagem qualitativa, tendo como objetivo identificar como a UFBA se mantém em seus momentos de aula remota ao utilizar-se do Moodle. Traz nesta perspectiva as categorias de análises voltadas para COVID-19 - Ensino Superior - TIC e políticas de informação.

Palavras-chave: Tecnologia da Informação e Comunicação. Leis de Acesso à Informação. COVID-19. Educação Superior.

\section{ICT for maintaining studies in a pandemic período at the Federal University of Bahia}

\begin{abstract}
One of the ways that Brazil's education found to maintain itself, in the period of isolation caused by the Coronavirus pandemic, was through remote classes adhered to by some Colleges Institutions, mostly private. The Federal University of Bahia, however, maintained, on the initiative of some teachers, some class moments in this remote format mediated by ICT, using the Moodle system, a Virtual Learning Environment - VLE, of which it was already a user. This article presents the discussion of the impacts that COVID -19 had on Brazil's Education, the public policies created to guide the reality of social isolation and how the information systems belong to UFBA were used in this pandemic period. This is a bibliographic search around different laws, with a qualitative approach, aiming to identify how UFBA remains in moments of remote class when it's using Moodle. In this perspective, it brings the analysis categories focused on COVID-19 College Education - ICT and policies information.
\end{abstract}

Keywords: Information and Communication Technology. Acess to Information Laws. COVID-19. College Education. 


\section{Introdução}

Em dezembro de 2019 a Organização Mundial de Saúde (OMS), por meio do seu escritório na China, foi informada sobre os primeiros casos de pessoas com sintomas de pneumonia de causa desconhecida. Esses casos aconteceram na cidade de Wuhan, província de Hubey. Em janeiro de 2020 a OMS publica as primeiras notícias sobre surtos desta doença e passa a realizar orientações, técnicas com conselhos de como detectar, testar e gerenciar casos sobre este vírus na época. No dia 12 de janeiro a China, segundo o site de notícias da OMS, compartilha publicamente a sequência genética da Covid - 19, logo após a primeira morte em meio a 41 casos confirmados em Wuhan. Neste contexto, apesar de parecidos, descartou-se outros dois tipos de Corona, o Coronavírus da Síndrome Respiratória Aguda Grave (SARS-Cov) e o Coronavírus da Síndrome Respiratória do Oriente Médio (MERS-CoV), como causadores do surto. Em fevereiro de 2020 a OMS, segundo o portal da Fiocruz, passou a chamar a doença de Covid-19, que significa Corona Virus Disease (Doença do Corona), e '19' porque se refere ao ano de 2019, quando surgiu.

O primeiro país depois da China, segundo a OMS, a contrair o vírus foi a Tailândia. A Organização das Nações Unidas (ONU) por meio do site da ONU News, do dia 14 de janeiro de 2020 informou

[...] a chegada à Tailândia do primeiro caso do novo vírus da mesma família da Síndrome Respiratória Aguda Grave, Sars. Em comunicado emitido na mesma segunda-feira, em Genebra, a agência da ONU destaca que este agente infeccioso está relacionado a um surto de pneumonia na China, que foi diagnosticado em uma pessoa que viajou para o território tailandês (ORGANIZAÇÃO DAS NAÇÕES UNIDAS, 2020, documento em linha).

Desde então, vários outros países foram afetados, alastrando-se pela Europa e elevando drasticamente não só o número de infectados quanto o número de mortos. Para garantir a diminuição de infectados pelo vírus e identificando que a contaminação se dá por meio do contato físico através da boca, olhos e nariz, as políticas públicas dos países afetados, determinam período de quarentena à população.

Neste contexto e com possível caso no Brasil, em 04 de fevereiro, sai a Portaria de número 188, de 3 de fevereiro de 2020 , que declara Emergência em Saúde Pública de Importância Nacional (ESPIN) em decorrência da Infecção Humana pelo novo Coronavírus (2019-nCoV). Nesta portaria o então Ministro da Saúde, Luiz Henrique Mandetta, estabelece no artigo segundo - Centro de Operações de Emergências em Saúde Pública (COE-nCoV) como mecanismo nacional da gestão coordenada da resposta à emergência no âmbito nacional.

A gestão do COE, fica, então, sob a responsabilidade da Secretaria de Vigilância em Saúde (SVS/MS), conforme a portaria. Portanto, compete ao $\mathrm{COE}$, dentre tantas outra ações, planejar, divulgar, acionar equipes de saúde, bem como contratar, para minimizar a situação do COVID-19.

Neste contexto, no dia 26 de fevereiro após comprovação do primeiro caso de Corona no Brasil, no Estado de São Paulo, o Ministério da Saúde publica no dia 12 de março de 2020, a portaria ํo 356/2020, que regulamenta medidas de enfrentamento de saúde pública contra o coronavírus a partir da Lei $n^{\circ}$ 13.979/20. O objetivo destas medidas era separar pessoas que apresentavam sintomas da doença, porém sem diagnóstico definido, devendo assim permanecerem isoladas para impedir o contágio de outras. Ela, determina, também, o isolamento da pessoa supostamente contaminada por 14 dias podendo ainda se prolongar por igual período.No artigo quarto, desta mesma portaria, é apresentada a medida de quarentena que tem como objetivo garantir a manutenção dos serviços de saúde em local certo, determinado e adota prazo de até 40 dias para que as pessoas estejam em casa, com o intuito de reduzir a transmissão comunitária e garantir a manutenção dos serviços de saúde no território.

Estas medidas, uma vez apresentadas no país, geram outros movimentos nos Estados e Municípios e promovem ações em relação aos diversos setores que compõem a sociedade local. Dentre elas, e a de maior interesse deste artigo, as medidas tomadas para a Educação, em especial do Ensino Superior no Estado da Bahia que refletem na sua Universidade Federal, campo de interesse deste estudo. Neste contexto, o artigo apresenta as tomadas de decisão pela Universidade Federal da Bahia (UFBA), com enfoque nas aulas remotas realizadas por meio de Tecnologias da Informação e Comunicação (TIC), utilizando-se da plataforma digital Moodle, em alguns cursos, para manutenção do ensino. 


\section{Procedimentos Metodológicos}

A realização desta pesquisa, está baseada em uma abordagem exploratória e descritiva, no que se refere ao contexto da Pandemia causada pelo Novo Coronavírus. Também, no âmbito da pesquisa qualitativa diante da análise do sistema digital Moodle da UFBA com especificidades na utilização dos usuários em tempos de Pandemia. Esta pesquisa assim se caracteriza porque se levantou informações sobre este objeto, delimitando assim um campo de trabalho, mapeando as condições de manifestação do mesmo. Para Rodrigues (2007, p. 29), uma pesquisa descritiva "[...] é o estudo que apresenta informações, dados, inventários de elementos constitutivos ou contíguos ao objeto". O método de abordagem deu-se pelo procedimento de pesquisa qualitativa.

No universo da pesquisa foram utilizados alguns dados bibliográficos, Leis relacionadas à Política Pública de Informação no Brasil, assim como, dados coletados com Núcleo de Ensino a Distância e Tecnologias de Educação (NEAD) e Superintedência de Tecnologia da Informação (STI) da Universidade Federal da Bahia, responsáveis pelas informações do Moodle quanto ao número de usuários cadastrados, acesso entre janeiro a maio de 2020 e cursos que demandaram salas virtuais no período da pandemia na UFBA. Este artigo está organizado de forma a discutir em um primeiro momento as Políticas Públicas do Ensino Superior em tempos de pandemia, seguido das características do Ensino Superior do Brasil e sua relação com as Tecnologias da Informação e Comunicação. Também aborda as características do sistema Moodle e SIGAA como plataformas utilizadas pela UFBA, especificidades na utilização do Moodle pelos usuários em período de isolamento social, como atendimento prestados pela equipe técnica a tais, Políticas Públicas de segurança e informação no Brasil. Por fim, as considerações finais da pesquisa.

\section{Política Pública de Ensino Superior em Período de Pandemia}

A partir da medida apresentada pelo Ministério da Saúde em relação a quarentena, o Ministério da Educação libera a portaria ํㅜ 343, de 17 de março de 2020 que dispõe sobre a substituição das aulas presenciais por aulas em meios digitais enquanto durar a situação de pandemia do Novo Coronavírus - COVID-19. Em seguida esta portaria recebe algumas alterações pela de ํㅜ 345, em que no artigo primeiro retira o termo 'limites da legislação em vigor', referente a autorização de ensino mediado por TIC.

Algumas instituições de Ensino Superior tomaram providências a partir das portarias supracitadas. Dentre as providências, suspensão das aulas, outras adiantaram período de férias e outras seguiram as aulas num formato de aulas remotas mediadas pelas Tecnologias da Informação e Comunicação.

Os Estados e Municípios contribuíram com estas medidas a partir de suas portarias que corroboram tanto com o Ministério de Saúde quanto o Ministério da Educação. Na Bahia, por exemplo, algumas notas técnicas foram apresentadas pelo Governo do Estado através da sua Secretaria da Saúde. No dia 28 de fevereiro de 2020 é liberada uma nota que trata dos critérios de definições para a notificação do novo Coronavírus, e no dia 16 de março de 2020, o governador da Bahia apresenta o decreto de ํo 19529 em que no artigo terceiro informa que poderá ser tomada a medida de isolamento e quarentena para o enfrentamento de emergência da saúde em relação a COVID-19. No decreto de no 19532 de 17 de março de 2020, no artigo sétimo, item dois, ficam suspensas atividades letivas por 30 dias nas unidades de ensino, públicas e particulares, a serem compensadas nos dias reservados para os recessos futuros.

\footnotetext{
Art. $7^{0}$ Em função dos casos confirmados de coronavírus nos Municípios de Salvador, Feira de Santana, Porto Seguro e Prado, ficam suspensos, pelo período de 30 (trinta) dias: I - os eventos e atividades com a presença de público superior a 50 (cinquenta) pessoas, ainda que previamente autorizados, que envolvem aglomeração de pessoas, tais como: eventos desportivos, religiosos, shows, feiras, circos, eventos científicos, passeatas e afins, bem como aulas em academias de dança e ginástica; II - as atividades letivas, nas unidades de ensino, públicas e particulares, a serem compensadas nos dias reservados para os recessos futuros; III - a abertura e funcionamento de zoológicos, museus, teatros e afins (BRASIL, 2020, documento em linha).
}

A partir destas medidas, a UFBA, lança à sua comunidade no dia 13 de março de 2020 a portaria de no 091, em que resolve suspender viagens e eventos do seu corpo docente e administrativo, bem como cancelar eventos que gerem aglomeração, além de recomendar que utilizem espaços amplos, caso atividades sejam de natureza curricular. Além disso, informa no artigo quarto que está atenta e poderá tomar outras medidas caso necessário. Sendo assim, no dia 19 de março de 2020, a UFBA 
lança a portaria $\mathrm{n}^{\circ} 103$ que dispões sobre a suspensão, por tempo indeterminado, todas as atividades acadêmicas e administrativas. A portaria ainda faz uma ressalva sobre as atividades essenciais, a saber, as que servem ao combate da Covid-19, bem como as que, se descontinuadas ou não, realizadas remota ou presencialmente, podem causar danos irreparáveis ao patrimônio e à instituição.

Desde então, a UFBA suspende as suas aulas, porém, alguns cursos, seja da graduação e pós graduação lato sensu e stricto sensu, continuam a desenvolver atividades acadêmicas, em um nível de saber teórico, por uma iniciativa de seus professores. A partir de dados disponibilizados pelo Núcleo de Ensino a Distância e Tecnologias de Educação (NEAD) e Superintedência de Tecnologia da Informação (STI) da Universidade Federal da Bahia, recebeu um aumento nas solicitações para criação de salas virtuais com a finalidade de manutenção dos estudos de forma remota.

Art. $1^{\circ}$ Suspender, por tempo indeterminado, todas as atividades acadêmicas e administrativas na Universidade Federal da Bahia, ressalvadas as atividades essenciais, a saber, as que servem ao combate da COVID-19, bem como as que, se descontinuadas ou não realizadas remota ou presencialmente, podem causar danos irreparáveis ao patrimônio e à instituição (UNIVERSIDADE FEDERAL DA BAHIA, 2020a, documento em linha).

Dando sequência à proposta deste artigo, vale ressaltar neste contexto, as características e legislação voltadas para as políticas públicas de informação no Brasil, assim como as Tecnologias da Informação e Comunicação sendo o meio mais propício em tempo de pandemia para atender não só a realidade da UFBA, como de outros setores da sociedade.

\subsection{Política Pública de Informação no Brasil}

Em meio ao isolamente social como forma de controle ao avanço do contágio da Covid-10, a TIC ampliou a mediação devido a necessidade de manutenção dos estudos de forma remota. Para tanto, se faz necessário enfatizar a importância do entendimento da legislação vigente que trata da política pública de informação no Brasil. A política de informação, sociedade da informação, internet, institucionalização da informação e o Estado fazem parte de algumas discussões no que diz respeito ao nexo da informação, com a política seria então estabelecido por sua inclusão na esfera de intervenção do Estado, agora não só como dimensão de racionalidade administrativa, mas como fator estratégico do desenvolvimento científico-tecnológico (GONZÁLEZ DE GÓMEZ, 2002). Conforme Jardim (1995 apud GONZÁLEZ DE GÓMEZ, 2002, p. 28):

Entre alguns dos principais fatos que sinalizam a constituição de um campo prático-discursivo diferenciado e
relativamente autônomo das políticas de informação, cabe destacar o "Weinberg Report" (U.S. President's Science
and Advisory Commitee, 1963) do governo norte-americano e as agendas internacionais estabelecidas pela
Organização das Nações Unidas para a Educação, Ciência e Cultura (Unesco). Se o primeiro documento define como
escopo e abrangência de uma política de informação a transferência de informação científica, sob a responsabilidade
do governo - que por sua vez convoca as competências de uma intelligentzia técnica -, as intervenções da Unesco
dirigiam-se a estabelecer um programa intergovernamental e cooperativo para promover e otimizar o acesso e uso
da informação, buscando superar as brechas científico-informacionais entre países centrais e periféricos e tendo
estes últimos como alvo principal.

O olhar mais amplo dado a informação é apresentado por González de Gómez (2002) por meio de citação de Castells (1999) em que há uma diferença entre o sentido dado pela sociedade. A sociedade da informação designava a informação à comunicação do conhecimento, enquanto a sociedade detentora de novas tecnológias integradas a organização social atribuiu sentindo informacional à informação. No entanto, as leis apresentadas a seguir compoem as diretrizes do governo eletrônico e governança infomacional em que a política e informação desdobram-se para contextualizar democracia, ciclo de vida da informação, tratamento, classificação.

A Lei de Acesso à Informação (LAI), n¹2.527 de 18 de novembro de 2011 que dispõe sobre os procedimentos a serem observados pela União, Estados, Distrito Federal e Municípios, com o fim de garantir o acesso a informações previsto no inciso XXXIII do art. $5^{\circ}$, no inciso II do $\S 3^{\circ}$ do art. 37 e no $\S 2^{\circ}$ do art. 216 da Constituição Federal (BRASIL, 2011), ainda que relativamente recente a promulgação após 23 anos, desdobrasse para um marco institucional para a política pública da informação, política pública de dados abertos, transparência pública, accountability, comunicação da informação, sistema da informação, tecnologia da informação. Lei que garante a qualquer usuário acesso as informações de seus devidos interesses. 
Quadro 1 - Regulamentação da Lei de acesso à informação (LAI) em nível Federal

LEGISLACÃO

Decreto $\mathrm{n}^{\circ} 7.724$, de 16 de maio de 2012

Decreto $\mathrm{n}^{\circ} 7.845$, de 14 de novembro de 2012

Decreto $n^{\circ} 8.777$, de 11 de maio de 2016
Art. 3 Para os efeitos deste Decreto, considera-se:

I - informação - dados, processados ou não, que podem ser utilizados para produção e transmissão de conhecimento, contidos em qualquer meio, suporte ou formato;

II - dados processados - dados submetidos a qualquer operação ou tratamento por meio de processamento eletrônico ou por meio automatizado com o emprego de tecnologia da informação;

III - documento - unidade de registro de informações, qualquer que seja o suporte ou formato;

IV - informação sigilosa - informação submetida temporariamente à restrição de acesso público em razão de sua imprescindibilidade para a segurança da sociedade e do Estado, e aquelas abrangidas pelas demais hipóteses legais de sigilo;

V - informação pessoal - informação relacionada à pessoa natural identificada ou identificável, relativa à intimidade, vida privada, honra e imagem;

VI - tratamento da informação - conjunto de ações referentes à produção, recepção, classificação, utilização, acesso, reprodução, transporte, transmissão, distribuição, arquivamento, armazenamento, eliminação, avaliação, destinação ou controle da informação;

VII - disponibilidade - qualidade da informação que pode ser conhecida e utilizada por indivíduos, equipamentos ou sistemas autorizados;

VIII - autenticidade - qualidade da informação que tenha sido produzida, expedida, recebida ou modificada por determinado indivíduo, equipamento ou sistema;

IX - integridade - qualidade da informação não modificada, inclusive quanto à origem, trânsito e destino;

X - primariedade - qualidade da informação coletada na fonte, com o máximo de detalhamento possível, sem modificações;

XI - informação atualizada - informação que reúne os dados mais recentes sobre o tema, de acordo com sua natureza, com os prazos previstos em normas específicas ou conforme a periodicidade estabelecida nos sistemas informatizados que a organizam; e

XII - documento preparatório - documento formal utilizado como fundamento da tomada de decisão ou de ato administrativo, a exemplo de pareceres e notas técnicas.

Art. $2^{\circ}$ Para os efeitos deste Decreto, considera-se:

I - algoritmo de Estado - função matemática utilizada na cifração e na decifração, desenvolvido pelo Estado, para uso exclusivo em interesse do serviço de órgãos ou entidades do Poder Executivo federal;

II - cifração - ato de cifrar mediante uso de algoritmo simétrico ou assimétrico, com recurso criptográfico, para substituir sinais de linguagem clara por outros ininteligíveis por pessoas não autorizadas a conhecê-la;

III - código de indexação - código alfanumérico que indexa documento com informação classificada em qualquer grau de sigilo;

IV - comprometimento - perda de segurança resultante do acesso não autorizado;

V - contrato sigiloso - ajuste, convênio ou termo de cooperação cujo objeto ou execução implique tratamento de informação classificada;

VI - credencial de segurança - certificado que autoriza pessoa para o tratamento de informação classificada;

VII - credenciamento de segurança - processo utilizado para habilitar órgão ou entidade pública ou privada, e para credenciar pessoa para o tratamento de informação classificada;

VIII - decifração - ato de decifrar mediante uso de algoritmo simétrico ou assimétrico, com recurso criptográfico, para reverter processo de cifração original;

IX - dispositivos móveis - equipamentos portáteis dotados de capacidade computacional ou dispositivos removíveis de memória para armazenamento;

$X$ - gestor de segurança e credenciamento - responsável pela segurança da informação classificada em qualquer grau de sigilo no órgão de registro e posto de controle;

XI - marcação - aposição de marca que indica o grau de sigilo da informação classificada;

XII - medidas de segurança - medidas destinadas a garantir sigilo, inviolabilidade, integridade, autenticidade e disponibilidade da informação classificada em qualquer grau de sigilo;

XIII - órgão de registro nível 1 - ministério ou órgão de nível equivalente habilitado pelo Núcleo de Segurança e Credenciamento:

XIV - órgão de registro nível 2 - órgão ou entidade pública vinculada a órgão de registro nível 1 e por este habilitado;

XV - posto de controle - unidade de órgão ou entidade pública ou privada, habilitada, responsável pelo armazenamento de informação classificada em qualquer grau de sigilo;

$\mathrm{XVI}$ - quebra de segurança - ação ou omissão que implica comprometimento ou risco de comprometimento de informação classificada em qualquer grau de sigilo;

XVII - recurso criptográfico - sistema, programa, processo, equipamento isolado ou em rede que utiliza algoritmo simétrico ou assimétrico para realizar cifração ou decifração; e

XVIII - tratamento da informação classificada - conjunto de ações referentes a produção, recepção, classificação, utilização, acesso, reprodução, transporte, transmissão, distribuição, arquivamento, armazenamento, eliminação, avaliação, destinação ou controle de informação classificada em qualquer grau de sigilo.

Art. ${ }^{\circ}$ Para os fins deste Decreto, entende-se por:

I - dado - sequência de símbolos ou valores, representados em qualquer meio, produzidos como resultado de um processo natural ou artificial;

II - dado acessível ao público - qualquer dado gerado ou acumulado pelo Governo que não esteja sob sigilo ou sob restrição de acesso nos termos da Lei n 12.527 , de 18 de novembro de 2011 .

III - dados abertos - dados acessíveis ao público, representados em meio digital, estruturados em formato aberto, processáveis por máquina, referenciados na internet e disponibilizados sob licença aberta que permita sua livre utilização, consumo ou cruzamento, limitando-se a creditar a autoria ou a fonte; 
IV - formato aberto - formato de arquivo não proprietário, cuja especificação esteja documentada publicamente e seja de livre conhecimento e implementação, livre de patentes ou qualquer outra restrição legal quanto à sua utilização; e

V - Plano de Dados Abertos - documento orientador para as ações de implementação e promoção de abertura de dados de cada órgão ou entidade da administração pública federal, obedecidos os padrões mínimos de qualidade, de forma a facilitar o entendimento e a reutilização das informações.

Art. $3^{\circ}$ A Política de Dados Abertos do Poder Executivo federal será regida pelos seguintes princípios e diretrizes: I - observância da publicidade das bases de dados como preceito geral e do sigilo como exceção;

II - garantia de acesso irrestrito às bases de dados, as quais devem ser legíveis por máquina e estar disponíveis em formato aberto;

III - descrição das bases de dados, com informação suficiente para a compreensão de eventuais ressalvas quanto à sua qualidade e integridade;

IV - permissão irrestrita de reuso das bases de dados publicadas em formato aberto;

$\mathrm{V}$ - completude e interoperabilidade das bases de dados, as quais devem ser disponibilizadas em sua forma primária, com o maior grau de granularidade possível, ou referenciar as bases primárias, quando disponibilizadas de forma agregada;

VI - atualização periódica, de forma a garantir a perenidade dos dados, a padronização de estruturas de informação e o valor dos dados à sociedade e atender às necessidades de seus usuários; $\mathrm{e}$

VII - designação clara de responsável pela publicação, atualização, evolução e manutenção de cada base de Fonte: Brasil (2012a; 2012b; 2016).

dado aberta, incluída a prestação de assistência quanto ao uso de dados.

Os decretos $n^{\circ} 7.724, n^{\circ} 7.845, n^{\circ} 8.777$ são os principais que tratam da regulamentação da LAI. O decreto $n^{\circ} 7.724$ de 16 de maio de 2016, trata da transparência e acesso à informações conforme descreve o artigo terceiro acima quanto a informação, dados processados, documento, informação sigilosa e pessoal, tratamento da informação, disponibilidade, autenticidade, integridade, primariedade, informação atualizada, documento preparatório. Como também, neste decreto são apresentadas transparência ativa no capítulo terceiro que trata de divulgação de informações produzidas dos órgãos públicos e entidades nos seus sítios da internet para acesso coletivo sob gestão e padronização da Secretaria de Comunicação Social da Presidência da República. A transparência passiva no capítulo quatro está relacionada ao Serviço de Informação ao Cidadão (SIC), solicitação ou pedido de acesso à informação. A abrangência dessas informações são abordadas neste decreto pelo qual o grau e prazo do sigilo estão sob classificação de tais informações. No entanto, a busca e o fornecimento da informação são gratuitos, ressalvada a cobrança do valor referente ao custo dos serviços e dos materiais utilizados, tais como reprodução de documentos, mídias digitais e postagem (BRASIL, 2012a).

A classificação das informações por meio do núcleo de segurança e credenciamento é tratada no decreto $n^{\circ} 7.845$ de 14 de novembro de 2012. No artigo segundo acima, são descritos o algoritmo do Estado, cifração, código de indexação, comprometimento, contrato sigilo, credencial e credenciamento de segurança, decifração, dispositivos móveis, gestor de segurança e credenciamento, marcação, medidas de segurança, órgãos de registro nível 1 e 2 , posto de controle, quebra de segurança, recurso criptográfico, tratamento da informação classificada. Dentre os pontos abordados no decreto, o sistema de informação, o tratamento da informação classificada deverão ser utilizados sistemas de informação e canais de comunicação seguros que atendam aos padrões mínimos de qualidade e segurança definidos pelo Poder Executivo federal (BRASIL, 2012b).

A política de dados descrita acima no artigo segundo do decreto $n^{\circ} 8.777$ de 11 de maio de 2016, os dados, dado acessível ao público, dados abertos, formato aberto, plano de dados aberto são abordados, assim como alguns pontos importantes no decreto ao que tange a cultura de transparência pública e a governança (BRASIL, 2016).

O fortalecimento da democracia por meio do direito a informação pública faz parte da globalização das sociedades. Sorj (2003) alerta sobre diferença entre os processos de globalização que consiste nas transformações sociais mais fortemente impulsionadas pelo mercantilismo, revolução industrial e especialmente no século XX caracterizado pelo capitalismo e a democracia liberal através dos processos sociais, culturais, políticos, econômicos e tecnológicos. "Enquanto a globalização das sociedades expressa-se no início da formação de uma opinião pública mundial, unificada em torno de temas da defesa dos direitos humanos e de acesso universal a bens de consumo coletivo" (SORJ, 2003, p.12). Sorj (2003) pontua diferença entre expectativa e realidade quanto a igualdade instaurada pela confusão entre democratização do mundo e globalização da igualdade.

No Brasil, a transparência pública foi marcada entre os anos de 2000 à 2012 pela Lei de Responsabilidade Fiscal (LRF) n 101, de 4 de maio de 2000 e Lei complementar $n^{\circ} 131$, de 27 de maio de 2009, que é uma lei complementar que trata da transparência na gestão fiscal das finanças públicas dando compreensão as responsabilidades da União, Estado, Distrito 
Federal e Municípios que diz respeito às atribuições dos Poderes Legislativo, Executivo, Tribunais de Contas da União, Estado e Município, Poder Judiciário e Ministério Público, integrando controle de despesas, execução orçamentária e cumprimento de metas, lei orçamentária anual e diretrizes orçamentárias.

Em 2003, pelo Conselho da Transparência Pública e Combate à Corrupção (CTPCC) e pela Controladoria Geral da União (CGU). O CTPCC por meio do decreto $n^{\circ} 4.923$, de 18 de dezembro de 2003, que dispõe sobre o Conselho de Transparência Pública e Combate à Corrupção, órgão colegiado e consultivo vinculado à Controladoria-Geral da União, tem como finalidade sugerir e debater medidas de aperfeiçoamento dos métodos e sistemas de controle e incremento da transparência na gestão da administração pública, e estratégias de combate à corrupção e à impunidade (BRASIL, 2003a). O CGU por meio da lei $n^{\circ}$ 10.683, de 28 de maio de 2003, que dispõe sobre a organização da Presidência da República e dos Ministérios passou diversas mudanças por meio de veto, conversão e revogação de medidas provisórias.

Em 2005, o Portal da Transparência e o Pregão Executivo também fizeram parte dos marcos instituicionais brasileiro. O Portal da Transparência do Poder Executivo por meio do decreto $n^{\circ} 5.482$, de 30 de junho de 2005, que trata do sítio eletrônico à disposição na Rede Mundial de Computadores - Internet, tem por finalidade veicular dados e informações detalhados sobre a execução orçamentária e financeira da União (BRASIL, 2005a). O Pregão Executivo por meio do decreto n 5.450 de 31 de maio de 2005, descrito pelo artigo primeiro como, modalidade de licitação pregão, na forma eletrônica, de acordo com o disposto no $\S 1^{\circ}$ do art. $2^{\circ}$ da Lei n 10.520 , de 17 de julho de 2002, destina-se à aquisição de bens e serviços comuns, no âmbito da União, e submete-se ao regulamento estabelecido neste Decreto (BRASIL, 2005b).

Em 2007, pelo Sistema de Gestão de Convênios e Contratos de Repasse (SICONV) e em 2008 pelo Cadastro Nacional de Empresas Inidôneas e Suspensas (CEIS) também fizeram parte das medidas de transparência pública no Brasil. O SICONV por meio do decreto $n^{\circ} 6.170$ de 25 de julho de 2007, dispõe sobre as normas relativas às transferências de recursos da União mediante convênios e contratos de repasse, e dá outras providências (BRASIL, 2007), pelo qual, passou por algumas alterações entre os anos de 2011 e 2016. O CEIS apresenta a relação de empresas e pessoas físicas que sofreram sanções que implicaram a restrição de participar de licitações ou de celebrar contratos com a Administração Pública (CADASTRO NACIONAL DE PESSOAS INIDÔNEAS E SUSPENSAS, 2020), com desdobramentos nas leis: Lei Anticorrupção $n^{\circ} 12.846$, de 1 de agosto de 2013, Lei de Licitações n 8.666, de 21 de junho de 1993, Lei do Pregão n 10.520, de 17 de julho de 2002, Lei de Improbidade Administrativa $n^{\circ}$ 8.429, de 2 de junho de 1992, Lei Eleitoral $n^{\circ}$ 9.504, de 30 de setembro de 1997, Lei Orgânica do TCU n 8.443, de 16 de julho de 1992, Lei de Crimes Ambientais n 9.605, de 12 de fevereiro de 1998, Lei ANTT e ANTAQ n० 10.233, de 5 de junho de 2001.

Em 2011 e 2012 o accountability, a participação social social fizeram parte dos princípios do Governo Aberto, criado em setembro de 2011 e conta, atualmente, com a adesão de mais de 70 países e de 15 governos subnacionais (OPEN GOVERNMENT PARTNERSHIP, 2018, p.5)

A democratização eletrônica é categorizada por Bellamy e Taylor (1998) e interpretada por Akutsu e Pinho (2002) de três maneiras possibilitadas pela Rede Mundial de Computadores - Internet, com a comercialização da informação, automação de serviços públicos e ao possibilitar o acesso a informações a um maior número de pessoas, com maior rapidez e menor custo (AKUTSU; PINTO, 2002, p. 4), assim como pressupostos da teoria da sociedade da informação desenvolvida por Bell (1977) por força do expansão das TIC.

Estar ciente da democratização do acesso a estas informações, faz-se importante neste contexto de pandemia não só pela realidade educacional de algumas IES, como também pelas questões da sociedade em geral relacionadas ao direito e demandas específicas de informações diante da pandemia causada pela Covid-19.

\subsection{TIC no Ensino Superior: Universidade Federal da Bahia em período de pandemia}

Na Universidade Federal da Bahia, as TIC utilizadas como ambiente virtual de aprendizagem (AVA) são o SIGAA e o Moodle, sistemas mediadores, como também, os que promovem a democratização do acesso a informações, conteúdos didáticos para 
a comunidade acadêmica. Para as demandas do Ensino Superior, estes sistemas são fundamentais na medida em que promovem continuidade de formação de seus estudantes mesmo a distância.

Segundo Saviani (2010, p. 59) o papel da Educação Superior tem como objetivo formar os profissionais dos mais diferentes tipos requeridos pela sociedade. A Educação Superior complementa o Sistema Nacional de Educação:

Do ponto de vista das relações com a sociedade a educação superior cumpre o papel de formar os profissionais de nível superior por ela requeridos. Assim, diferentemente do ensino fundamental, que jamais é profissionalizante, e do ensino médio que pode ou não ser profissionalizante, o ensino superior é necessariamente profissionalizante. Ou seja, todos os cursos de graduação, ainda aqueles que parecem muito distantes da destinação profissional, em última instância desembocam no exercício de determinada atividade profissional.

Importante destacar que o perfil do profissional formado em uma Instituição de Ensino Superior deve contemplar o desenvolvimento de competências a fim de fazer jus à profissão escolhida e por meio dela resolver problemas da sociedade.

Neste contexto as Diretrizes Curriculares Nacionais determinam o conhecimento, a habilidade e atitude que o estudante deve desenvolver ao longo da sua graduação. Para se certificar se a Instituição atendeu a estas demandas desde o perfil do estudante às condições oferecidas para o Ensino Superior, o Instituto de Pesquisa em Educação, Anísio Teixeira (INEP) apresenta na Portaria no 586, de 9 de julho de 2019 como um dos indicadores de qualidade da Educação Superior, o Conceito Exame Nacional de Desempenho do Estudante (Enade) que avalia, o rendimento dos concluintes dos cursos de graduação em relação aos conteúdos programáticos previstos nas diretrizes curriculares dos cursos, o desenvolvimento de competências e habilidades necessárias ao aprofundamento da formação geral e profissional, e o nível de atualização dos estudantes com relação à realidade brasileira e mundial. Para a realização deste exame o estudante se depara com duas etapas importantes, um questionário e a prova. Esta por sua vez constituída por duas áreas do saber a serem aprofundadas, geral e específicas.

Por mais específicos que sejam os conteúdos e competências avaliadas, a concepção e uso de Tecnologias é um dos requisitos a serem avaliados pelo INEP em relação ao estudante, tanto no questionário quanto na prova. No questionário, pergunta-se sobre o que a IES oferece de tecnologia à sua comunidade discente, e na prova, como o estudante concebe a realidade das Tecnologias da Informação e Comunicação em suas diversas vertentes. Neste contexto, as Universidades, sejam elas públicas ou privadas, vem se organizando ao longo do tempo, conforme suas realidades, para proporcionar aos seus estudantes e comunidade acadêmica em geral, não só uso de equipamentos tecnológicos, como computador, aparelhos de retroprojeção multimídia, bem como conexão e sistemas digitais sejam para organizar os serviços administrativos, seja para propiciar ao corpo docente uma ferramenta de organização pedagógica como os Ambientes Virtuais de Aprendizagem. Segundo Santaella (2003, p. 23):

Já está se tornando lugar-comum afirmar que as novas tecnologias da informação e comunicação estão mudando não apenas as formas do entretenimento e do lazer, mas potencialmente todas as esferas da sociedade: o trabalho (robótica e tecnologias para escritórios), gerenciamento político, atividades militares e policiais (a guerra eletrônica), consumo (transferência de fundos eletrônicos), comunicação e educação (aprendizagem a distância), enfim, estão mudando toda a cultura em geral.

Desde as duas últimas décadas do século passado que as Tecnologias da Informação e Comunicação (TIC) vem adentrando de maneira muito significativa o espaço educacional no Brasil. Vale ressaltar que em tempos atuais se vive uma era digital coadunada com grandes demandas sociais que contribuem direta e indiretamente na ampliação de uma cultura que prima pelo uso das TIC para solucionar problemas de diferentes setores da sociedade. Na Educação Superior as Tecnologias Digitais da Informação e Comunicação contribuem em um primeiro momento como repositório e ambiente de compartilhamento de atividades e material de apoio, em segundo momento para a oferta de Educação à Distância. Os AVA passam a ser link entre docentes e discentes interessados pela modalidade EaD. No entanto, as plataformas utilizadas possuem atribuições distintas que permitem ao estudante autonomia e um certo autodidatismo, também, depósito de diferentes materiais de cunho pedagógico, em algumas dispõe de bibliotecas digitais com a finalidade dos conteúdos serem contemplados pelos alunos em sua formação. Sistemas como o Moodle e o SIGAA são hoje exemplos de plataformas digitais com especificidades diferentes nas suas funcionalidades, presentes em algumas Instituições de Ensino Superior (IES) no Brasil, em especial nas Universidades públicas. As mesmas são utilizadas pela UFBA e contribuíram diferentemente, sobremaneira, para o formato a manutenção dos estudos em período de isolamento social, causado pela pandemia do Novo Coronavírus. Para apresentar como esses sistemas contribuíram para a manutenção do ensino nesta IES, embora de forma 
um tanto restrita, apresenta-se, a seguir definições e breves características de cada um desses sistemas, que, embora atendam a realidade das IES, são diferentes entre elas quanto aos seus objetivos, ferramentas, layouts, também no que diz respeito as suas usabilidades, navegabilidade e interatividade.

A começar pelo SIGAA, Sistema Integrado de Gestão de Atividades Acadêmicas, faz-se importante saber que ele nasceu em 2005, criado pela Universidade Federal do Rio Grande do Norte (UFRN). À época as Universidades possuíam um programa, mas para apoio às questões administrativas, como era o SIPAC, Sistema Integrado de Patrimônio, Administração e Contratos, que além de organizar questões relacionadas ao financeiro da instituição, também servia para registro e controle de Material, Passagens, Diárias, Suprimento de Fundos, Auxílio Financeiro.

O SIGAA é resultado da proposta acadêmica apresentada no Plano de Desenvolvimento Institucional (PDI) da UFRN nas áreas de Tecnologia da Informação e Comunicação. Desde que foi implantado, o SIGAA recebeu apoio do MEC no processo de ajustes, inclusive para atender demandas do ensino básico. Com o passar do tempo o SIGAA, conforme histórico da UFRN, ampliou-se e foi institucionalizado nas demais Universidades Públicas, hoje também presente na UFBA. A ferramenta tem como funcionalidades um repositório de material didático pedagógico para o docente, acompanhamento das atividades solicitadas, comunicação em fórum entre docentes e discentes. Os usuários que são a comunidade acadêmica, fazem uso da ferramenta para acessar informações e materiais independentes de período de aula, assim como no presente período de pandemia. O SIGAA se caracteriza como Ambiente Virtual de Aprendizagem (AVA) em que o docente disponibiliza material de leitura, comunica-se de forma assíncrona com seus docentes e desenvolve conhecimentos teóricos.

Figura 1 - Interface do SIGAA para o docente

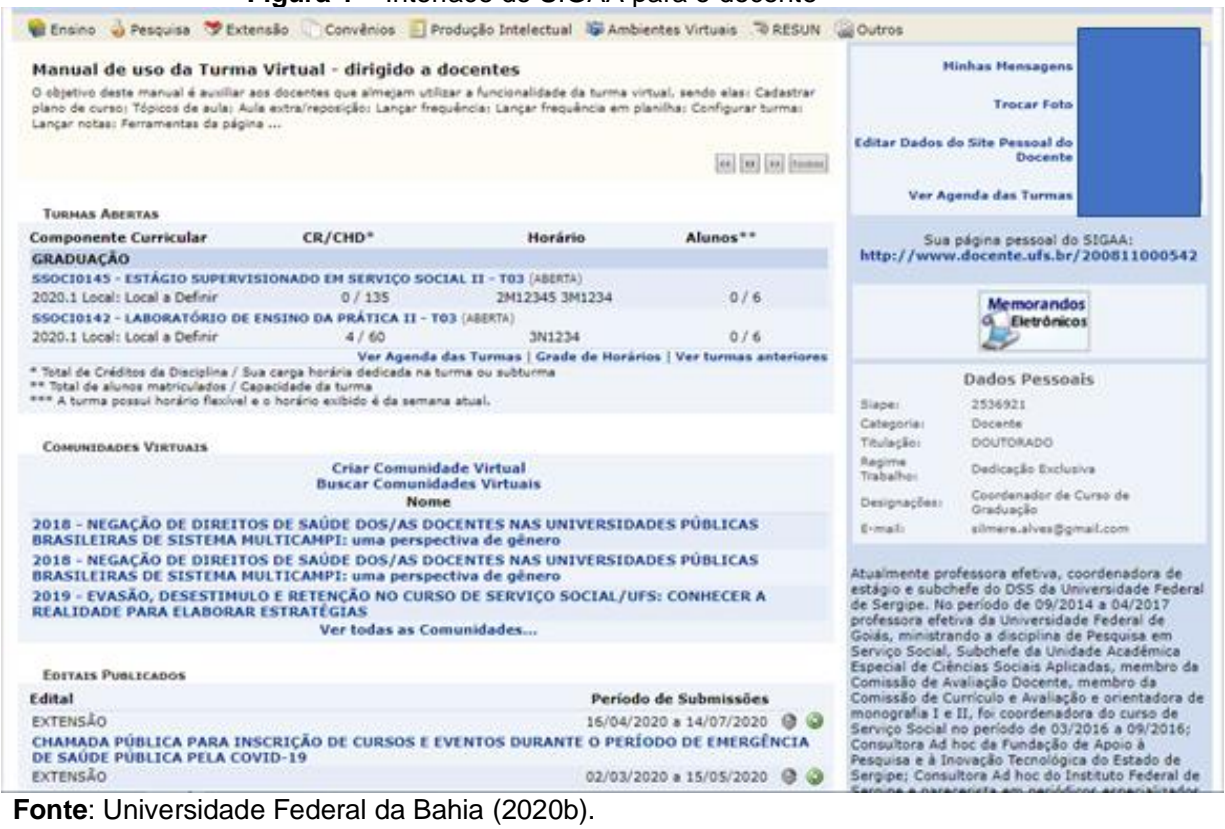

Para melhor compreender o SIGAA, a Figura 1 acima apresenta a visualização da ferramenta quando se trata de acesso realizado por docente. Dentre as funcionalidades, na parte superior que contém ensino, pesquisa, extensão, convênios, produção intelectual, ambientes virtuais, RESUN, dentre outros. No ensino é possível gerenciar orientação de pós-graduação, cadastrar notas, gerenciar plano de de curso, grade de horários, consultar turmas, consultar cursos, componentes curriculares, unidades acadêmicas, defesas de pós-graduação, calendário acadêmico, declaração de disciplinas ministradas. Enquano o moodle apresenta algumas outras funcionalidades.

O Modular Object-Oriented Dynamic Learning Environment (MOODLE) ou Ambiente Modular de Aprendizagem Dinâmica Orientada a Objetos, é um sistema web voltado para o ensino e aprendizagem criado por Martin Dougiamas, cientista da computação e Pedagogo, no início dos anos 90 (CARLINI; TARCIA, 2010) desenvolver um software de código aberto segundo (MACHADO, 2000), com objetivo de ser flexível, compatível e de fácil modificação. 
A primeira versão do Moodle foi lançada em 20 de agosto de 2002, desde então, segundo Maragnato, Ramos e Oliveira (2015) ele ja sofreu várias modificações. Vale ressaltar que a proposta pedagógica deste Ambiente Virtual de Aprendizagem promove o trabalho colaborativo de ensino sem exigir conhecimentos aprofundados em informática, além de possuir uma aplicabilidade que facilita o preparo da dinâmica do estudo na ferramenta.

Figura 2 - Layout do Moodle para o docente

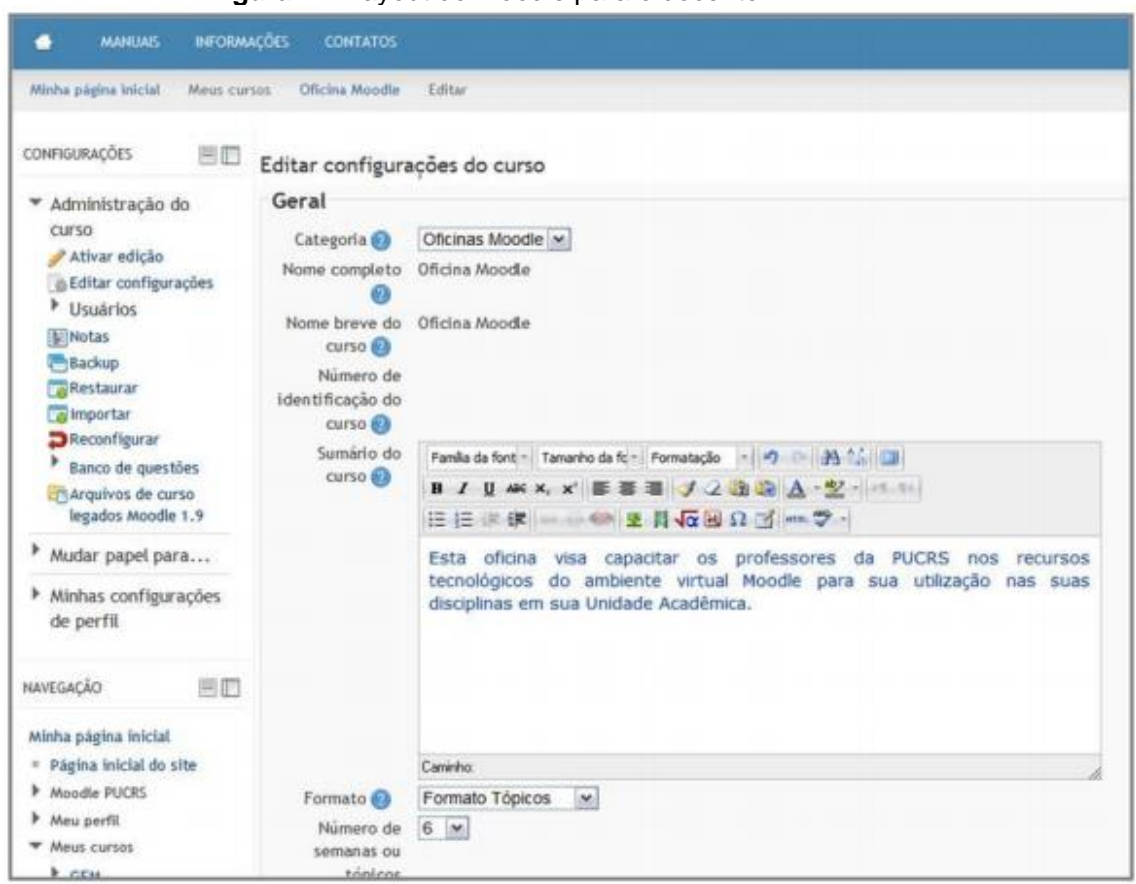

Fonte: Pontifícia Universidade Católica do Rio Grande do Sul (2012).

Conforme Figura 2 acima, as funcionalidades do Moodle, nessa oportunidade de acesso do docente, são separadas por blocos. Este bloco reúne os links de navegação da página Moodle de forma geral e não apenas referente ao ambiente do curso. Ali se encontram 'atalhos' para diversas páginas (PONTIFÍCIA UNIVERSIDADE CATÓLICA DO RIO GRANDE DO SUL, 2012). No campo superior é possível acessar manuais, informações e contatos. Um pouco abaixo, minha página inicial, meus cursos, oficina moodle, edital, no qual, o campo 'meus cursos' está na imagem acima. Na coluna ao lado esquerdo algumas funcionalidades, os três itens existentes neste bloco são Administração do Curso, 'Mudar papel para', e 'Minhas Configurações de Perfil' (PONTIFÍCIA UNIVERSIDADE CATÓLICA DO RIO GRANDE DO SUL, 2012).

No item Administração do Curso são apresentadas as seguintes funcionalidades: Ativar Edição, Editar Configurações, Usuários, Notas, Backup, Restaurar, Importar, Reconfigurar, Banco de questões e Arquivos de curso legados MOODLE 1.9. (PONTIFÍCIA UNIVERSIDADE CATÓLICA DO RIO GRANDE DO SUL, 2012). Na segunda opção de editar configurações apresentadas na Figura 2, neste espaço podem ser estabelecidas todas as escolhas para o formato geral de um curso/disciplina, detalhadas na sequência (PONTIFÍCIA UNIVERSIDADE CATÓLICA DO RIO GRANDE DO SUL, 2012).

O monitoramento dos 78.973 usuários cadastrados de disponibilidade da ferramenta Moodle, se dar pelo registro do último acesso. Desde a suspensão das aulas na Universidade Federal da Bahia por tempo indeterminado, o Conselho Universitário manteve a TIC com suas funcionalidades habituais e uso de salas virtuais, por compor os sistemas institucionais que integram as atividades essenciais. Entre os meses de março e abril de 2020 houve um aumento na criação de salas virtuais no moodle segundo dados do NEAD e STI. Entre os 1.226 atendimentos prestados, por volta de 230 no mês de março e 62 no mês de abril foram para criação de sala virtuais. 


\section{Considerações Finais}

O esforço para manutenção dos estudos nesse período de incertezas causados pela Covid-19 maximizou a criação de salas virtuais na UFBA. A preocupação com a vida e a saúde de forma coletiva deu celeridade no uso do Moodle na ampliação da ferramenta para mediar aulas remotas, visto que o mesmo até então tinha como maior funcionalidade de repositório.

Para emergir e manipular informações, dados em ambiente virtual com maior frequência no âmbito da UFBA, se faz necessário relembrar à comunidade acadêmica sobre a política pública de informação brasileira, para que no uso em atividades de pesquisa, extensão, o entendimento da regulamentação para o tratamento, classificação das informações e política de dados auxilie na transparência e segurança na transmissão das informações para com a sociedade.

A UFBA se encontra em mais um desafio para proteger o direito ao ensino superior gratuito e de qualidade, controle da evasão educacional, assim como dar continuidade ao comprometimento ao desenvolvimento social, intelectual, atentos a fundamental importância da Universidade para reconstrução social, econômico em momento pós Covid-19, mas no enfrentamento diário de forma científica à toda a socidade.

\section{Referências}

AKUTSU, Luiz; PINHO, José Antônio Gomes de. Sociedade da Informação, accountability e democracia delegativa: investigação em portais no Brasil. RAP: Revista de Administração Pública, Rio de Janeiro, v. 36, n. 5, p. 723-745, set./out. 2002. Disponível em: http://bibliotecadigital.fgv.br/ojs/index.php/rap/article/view/6461/5045. Acesso em: 30 jun. 2020.

BELLAMY, Cristine; TAYLOR, John A. Governing in the information age. Buckingham, Open University Press, 1998.

BELL, Daniel. O advento da sociedade pós-industrial: uma tentativa de previsão social. São Paulo, Cultrix, 1977.

BRASIL. Lei Complementar $n^{\circ} 101$, de 4 de maio de 2000. Estabelece normas de finanças públicas voltadas para a responsabilidade na gestão fiscal e dá outras providências. Diário Oficial da União: Brasília, 5 maio. 2000. p. 1. Disponível em: http://www.planalto.gov.br/ccivil 03/Leis/LCP/Lcp101.htm. Acesso em: 18 abr. 2020.

BRASIL. Decreto $n^{\circ} 4.923$, de 18 de dezembro de 2003. Dispõe sobre o Conselho de Transparência Pública e Combate à Corrupção, e dá outras providências. Diário Oficial da União: Brasília, 19 dez. 2003a. p. 4. Disponível em: http://www.planalto.gov.br/ccivil 03/decreto/2003/D4923impressao.htm. Acesso em: 18 abr. 2020.

BRASIL. Lei n¹0.683, de 28 de maio de 2003. Dispõe sobre a organização da Presidência da República e dos Ministérios, e dá outras providências. Diário Oficial da União: Brasília, 29 maio. 2003b. p. 2. Disponível em: http://www.planalto.gov.br/ccivil 03/leis/2003/l10.683.htm. Acesso em: 18 abr. 2020.

BRASIL. Decreto $n^{\circ} 5.482$, de 30 de junho de 2005. Dispõe sobre a divulgação de dados e informação pelos órgãos e entidades da administração pública federal, por meio da Rede Mundial de Computadores - Internet. Diário Oficial da União: Brasília, 01 jul. $2005 a$. p. 4. Disponível em: http://www.planalto.gov.br/ccivil 03/ Ato2004-2006/2005/Decreto/D5482.htm. Acesso em: 18 abr. 2020.

BRASIL. Decreto n 5.450, de 31 de maio de 2005. Regulamenta o pregão, na forma eletrônica, para aquisição de bens e serviços comuns, e dá outras providências. Diário Oficial da União: Brasília, 1 jun. 2005b. p.5. Disponível em: http://www.planalto.gov.br/ccivil 03/ ato20042006/2005/decreto/d5450.htm. Acesso em: 18 abr. 2020.

BRASIL. Decreto ${ }^{\circ} 6.170$, de 25 de julho de 2007. Dispõe sobre as normas relativas às tranferências de recursos da União mediante convêncios e contratos de repasse, e dá outras providências. Diário Oficial da União: Brasília, 26 jul. 2007. Disponível em: http://www.planalto.gov.br/ccivil 03/ ato2007-2010/2007/decreto/d6170.htm. Acesso em: 18 abr. 2020.

BRASIL. Lei $n^{\circ} 12.527$, de 18 de novembro de 2011. Regula o acesso a informações previsto no inciso XXXIII do art. $5^{\circ}$, no inciso II do § $3^{\circ}$ do art. 37 e no $\S 2^{\circ}$ do art. 216 da Constituição Federal; altera a Lei no 8.112, de 11 de dezembro de 1990; revoga a Lei no 11.111, de 5 de maio de 2005, e dispositivos da Lei no 8.159, de 8 de janeiro de 1991; e dá outras providências. Diário Oficial da União: Brasília, Edição Extra, 18 nov. 2011. p. 1. Disponível em: http://www.planalto.gov.br/ccivil 03/ ato2011-2014/2011/lei/l12527.htm. Acesso em: 18 abr. 2020.

BRASIL. Decreto $n^{\circ} 7.724$, de 16 de maio de 2012. Regulamenta a Lei no 12.527, de 18 de novembro de 2011, que dispõe sobre o acesso a informações previsto no inciso XXXIII do caput do art. 5o , no inciso II do $\S 3^{\circ}$ do art. 37 e no $\S 2^{\circ}$ do art. 216 da Constituição. Diário Oficial da União: Brasília, Edição Extra, 16 maio. 2012a. Disponível em: http://www.planalto.gov.br/ccivil 03/ ato2011-2014/2012/Decreto/D7724.htm Acesso em: 18 abr. 2020.

BRASIL. Decreto $n^{\circ} 7.845$ de 14 de novembro de 2012. Regulamenta procedimentos para credenciamento de segurança e tratamento de informação classificada em qualquer grau de sigilo, e dispõe sobre o Núcleo de Segurança e Credenciamento. Diário Oficial da União: Brasília, 16 nov. 2012b. Disponível em: http://www.planalto.gov.br/ccivil 03/ ato2011-2014/2012/Decreto/D7845.htm. Acesso em: 18 abr. 2020.

BRASIL. Decreto $n^{\circ} 8.777$ de 11 de maio de 2016. Institui a política de dados abertos do poder executivo federal. Diário Oficial da União: Brasília, 12 maio. 2016. p. 21. Disponível em: http://www.planalto.gov.br/ccivil 03/ Ato2015-2018/2016/Decreto/D8777.htm. Acesso em 18 abr. 2020. 
CADASTRO NACIONAL DE EMPRESAS INIDÔNEAS E SUSPENSAS. 2020. Disponível em: http://www.portaldatransparencia.gov.br/pagina-interna/603245-ceis. Acesso em: 18 abr. 2020.

CARLINI, Alda; TARCIA, Rita Maria. 20\% a distância e agora?: orientações práticas para o uso de tecnologia de educação a distância no ensino presencial. São Paulo: Pearson Education do Brasil, 2010.

CASTELLS, Manuel. A sociedade em rede. São Paulo: Paz e Terra, 1999.

GONZÁLEZ DE GÓMEZ, Maria Nélida. Novos cenários políticos para a informação. Ciência da Informação, Brasília, v. 31, n. 1, p. 27-40, jan./abr. 2002. Disponível em: http://revista.ibict.br/ciinf/article/view/975/1013. Acesso em: 29 jun. 2020.

MACHADO, Júlio Henrique Araújo Pereira. Hyper-Automaton: hipertextos e cursos na web usando autômatos finitos com saída. 2000.148 f. Dissertação (Mestrado em Computação) - Universidade Federal do Rio Grande do Sul, Porto Alegre, 2000. Disponível em: https://lume.ufrgs.br/handle/10183/3417. Acesso em: 30 jun. 2020.

MARAGNATO, Cleber Cicero, RAMOS, Monica Parente; OLIVEIRA, Lucila Maria Pesce de. Estudo sobre o Uso do Moodle em Cursos de Especialização a Distância da Unifesp. Revista Brasileira de Educação Médica, Rio de Janeiro, v. 39, n. 4, p. 507-516, dez.

2015. Disponível em: http://www.scielo.br/scielo.php?script=sci arttext\&pid=S0100-55022015000400507\&lng=pt\&nrm=iso. Acesso em: 3 jul. 2020.

ORGANIZAÇÃO DAS NAÇÕES UNIDAS. OMS confirma caso do novo vírus da mesma família Sars na Tailândia. In: ORGANIZAÇÃO DAS NAÇÕES UNIDAS. ONU News. [S.I.], 14 jan. 2020. Disponível em: https://news.un.org/pt/story/2020/01/1700392. Acesso em: 3 jul. 2020.

OPEN GOVERNMENT PARTNERSHIP. 4 Plano de Ação Nacional em Governo Aberto. Brasília, 2018. Disponível em: https://www.gov.br/cgu/pt-br/governo-aberto/a-ogp/planos-de-acao/4o-plano-de-acao-brasileiro/4o-plano-de-acao-nacional portugues.pdf. Acesso em: 30 jun. 2020.

PONTIFÍCIA UNIVERSIDADE CATÓLICA DO RIO GRANDE DO SUL. Ambiente Virtual de Aprendizagem Moodle versão 2.2: Manual Moodle do Professor. Porto Alegre, 2012. Disponível em:

https://moodle.pucrs.br/pluginfile.php/1225804/mod resource/content/1/Moodle Manual do Professor V2.2 ed2.pdf. Acesso em: 30 jun. 2020.

RODRIGUES, Rui Martinho. Pesquisa Acadêmica: como facilitar o processo de preparação de suas etapas. São Paulo: Atlas, 2007.

SANTAELLA, Lúcia. Da cultura das mídias à cibercultura: o advento do pós-humano. Revista FAMECOS, n. 22, p. $23-32$, dez. 2003. Disponível em: http://revistaseletronicas.pucrs.br/ojs/index.php/revistafamecos/article/viewFile/3229/2493\&quot;. Acesso em: 30 jun. 2020.

SAVIANI. Dermeval. Sistema Nacional de Educação: o lugar da educação superior. Educativa: Revista de Educação, Goiânia, v. 13, n. 1, p. 45-66, jan./jun. 2010. Disponível em: http://seer.pucgoias.edu.br/index.php/educativa/article/view/1244/860. Acesso em: 30 jun. 2020.

SORJ, Bernardo. Brasil@povo.com: a luta contra desigualdade na Sociedade de Informação. Rio. Jorge Zahar, 2003.

UNIVERSIDADE FEDERAL DA BAHIA. Gabinete da Reitoria. Portaria n. 130, de 19 de março de 2020a. Dispõe sobre a suspensão das atividades na UFB.A, devido à disseminação do novo coronavírus (COVID-19). Disponível em: http://www.napeacessivel.ufba.br/noticias/portaria-n\%C2\%B0-1032020-ufba. Acesso em: 3 jul. 2020.

UNIVERSIDADE FEDERAL DA BAHIA. [Print da Interface do SIGAA para o docente]. Salvador: UFBA, 2020b. 